\section{Experimental Physical Chemistry}

By Prof. Farrington Daniels, Prof. Joseph Howard Mathews, Prof. John Warren Williams, Prof. Paul Bender and Prof. Robert A. Alberty. Fifth edition. Pp. xi +482 . (London: McGraw-Hill Publishing Company, Ltd., 1956.) 49 s.

T $\mathrm{HE}$ avowed object of this book is the same as that of the 1929 and later editions, namely, "to illustrate the principles of physical chemistry, to train in careful experimentation, to develop familiarity with apparatus, to encourage ability in research". The volume is representative of the teaching of the laboratory course at the University of Wisconsin. Part I contains fifty-nine sections each of which describes an experiment and consists of a short introduction, an account of theory, apparatus, procedure, calculations, practical applications, suggestions for further work and references. It is intended that the experiments should be carried out under the guidance of an instructor. The second part of the volume, occupying pp. 321-469, describes apparatus and techniques, particularly for more advanced work. No claim is made for completeness, and the authors have been guided by their own experiences. This part of the book is not very satisfactory because so many subjects are dismissed in so few words. Thus microscopy is discussed in thirty-two lines and spectroscopy (visible, ultra-violet and infra-red) is described in forty-six lines. However, there are some interesting sections such as that dealing with the use of electronics in physical chemistry (twenty-nine pages). The inside of the front cover gives a list of atomic weights while the back cover carries a table of four-figure logarithms. The first part of this book presents the results of considerable experience in the teaching of practical physical chemistry and staffs of universities may well find here useful suggestions for their practical courses.

E. F. G. Herington

\section{Acridines}

By R. M. Acheson. With a chapter by L. E. Orgel. (Chemistry of Heterocyclic Compounds : a Series of Monographs, Vol. 9.) Pp. xii +409 . (New York : Interscience Publishers, Inc. ; London : Interscience Publishers, Ltd., 1956.) 12.50 dollars.

$\mathrm{H}$ ETEROCYCLIC chemistry is poorly provided with comprehensive monographs, and this series is designed to provide a detailed treatment of the whole field. This book maintains the high stan. dard set by its predecessors. The anti-malarial and anti-bacterial properties of certain acridines led to an intensive, but somewhat unbalanced, development of acridine chemistry. In Albert's "Acridines", published in 1951, the pharmaceutical aspects are stressed, and the large amount of experimental technique included makes it an invaluable book for the specialist. Acheson, dealing inevitably with much the same information, has adopted a different approach. He has arranged the material in a more logical way; he has emphasized topics of general chemical interest, for example, the mechanism of reactions, and relegated details of individual compounds to a series of extensive and excellent tables. Thus, the book provides lively reading for those interested in heterocyclic chemistry, and also serves as a standard reference text-a rare combination of virtues. Acheson has included an excellent chapter on the acridine alkaloids. This work has its own intrinsic interest, but also illustrates how intensive work on individual compounds illuminates the chemistry of a whole class, in this case the polymethoxy and polyhydroxy acridines. The concise account of the absorption spectra of acridines is well written by Orgel. Some infra-red spectra are reproduced, unfortunately without comment. The text is almost completely free from trivial errors, but the index is not always adequate. M. F. GRUNDoN

\section{Dictionary of Microbiology}

By Morris B. Jacobs, Maurice J. Gerstein and Prof. William G. Walter. Pp. iv +276. (Princeton, N.J. : D. Van Nostrand Company, Inc.; London: Macmillan and Co., Ltd., 1957.) 50s. net.

ACORDING to the publishers' note, this dicA tionary contains some $\mathbf{5 , 0 0 0}$ entries giving "clear and explicit definitions of terms from the entire field of microbiology". The entries include systematic names and classification data for bacteria (Bergey's nomenclature), moulds, protozoa and viruses together with antibiotics, etc. Spot tests showed that entries were comprehensive and satisfactory in these fields but less good in other subjects normally included in modern microbiology. For example, there is no reference to eclipse phase, latent phase, lysogency, induction, kinetoplast, chemostat, auxotrophe, lecithinase, strepogenin or racemase. Biochemists will find definitions of some chemical terms somewhat superficial : the various amino-acids are listed and described as "involved in the meta. bolism of micro-organisms", while pyridoxin derivatives are "probably converted to amino-acid decarboxylases". Transforming Principle is referred to pneumococcal-type transformation only; plasmagenes are "genetic determinants in the broadest sense" ; an auxanogram refers to study of inhibitors, while an auxanograph refers to utilization of carbohydrate or nitrogen-bearing substances. In general, the dictionary contains much of use to all microbiologists, but is not of great assistance to the expert who requires precise definition of technical terms or elucidation of recent or uncommon words in his own field. E. F. GALE

\section{A Scientific Sampler}

Edited by Raymond Stevens, Howard F. Hamacher and Alan A. Smith. Pp. xviii +413. (Princeton, N.J. : D. Van Nostrand Company, Inc.; London : Macmillan and Co., Ltd., 1956.) 45s. net.

ATHUR D. LITTLE, Inc., is a research organ$A$ ization in the United States with a large staff devoted mainly to research in the applied sciences. Once a month the organization publishes an Industrial Bulletin in which the staff are given opportunities for describing their professional and extra. curricular interests in a form suitable for the lay reader. Over the past thirty years a wide range of topics has been considered, and the editors of the Bulletin have now brought a large number of them together to form a fascinating book. Some of the articles are more than twenty years old, but have been brought up to date by the addition of suitable footnotes. The variety of subjects covered is so great that it would need exhaustive treatment to cover them; few aspects of seience are unrepresented.

"The Scientific Sampler" is a book for which many specialists have been looking. The articles are brief, clearly written and could be used either for reference or as a bedside book. The editors should be congratulated, not only for their choice, in authors, but also for the way they have put the book together.

T. H. HAwKINS 